\title{
Optimization of a rapid one-step platelet- rich plasma preparation method using syringe centrifugation with and without carprofen
}

\author{
Jutarat Apakupakul ${ }^{1}$, Panpicha Sattasathuchana ${ }^{2}$, Phongsak Chanloinapha ${ }^{3}$ and Naris Thengchaisri ${ }^{2 *}$
}

\begin{abstract}
Background: Carprofen and platelet-rich plasma (PRP) are widely used in small animal clinical practice. Separation layers have been used during blood centrifugation to increase platelet yield. The objectives of this study were to (1) identify the optimal centrifugation force for the one-step PRP preparation, (2) determine whether there is an advantage to using carprofen in one-step PRP preparation, and (3) compare platelet morphology from one-step PRP preparation with and without carprofen. We hypothesized that injectable carprofen (emulsion formula) could be used successfully as the separation layer in PRP preparation.

Results: Samples from 14 healthy dogs were used to determine the optimal centrifugation force using one-step PRP preparation in a disposable syringe without carprofen, with forces set at 300, 500, 700, 900, 1100, 1300, and $1500 \mathrm{xg}$ for $5 \mathrm{~min}$. Optimum centrifugation force, plasma volume, and platelet concentrations of one-step PRP preparation were found and recovered at $900 \times g, 1.9 \pm 0.28 \mathrm{ml}$, and $260.50 \pm 58.39 \times 10^{3} \mathrm{cell} / \mu \mathrm{l}$, respectively. Samples from 12 healthy dogs were used to determine the optimal force (with forces set at 300, 500, 700, and 900 $\mathrm{xg}$ ) for 5 min using one-step PRP preparation with carprofen. Optimum centrifugation force, plasma volume, and platelet concentrations for one-step PRP preparation with carprofen were found and recovered at $500 \times \mathrm{xg}, 0.62 \pm$ $0.16 \mathrm{ml}$ and $948.50 \pm 261.40 \times 10^{3} \mathrm{cell} / \mu \mathrm{l}$, respectively. One-step PRP preparation with carprofen increased the platelet yield from baseline by 1.76 and 4.95 fold, respectively. Samples from 3 healthy dogs were used to observe platelet morphologies after centrifugation by scanning electron microscopy. Images of platelets on glass slides from both preparation methods revealed pseudopods emerging from the margins of the discoid platelets.
\end{abstract}

Conclusions: One-step PRP centrifugation both with and without carprofen increased the platelet yield, but using carprofen (emulsion formula) as a separation layer resulted in a higher platelet yield. The clinical usefulness of PRP products from these methods should be further investigated.

Keywords: Blood, Centrifugation, Dog, Platelet-rich plasma, Carprofen

\footnotetext{
*Correspondence: ajnaris@yahoo.com

${ }^{2}$ Department of Companion Animal Clinical Sciences, Faculty of Veterinary

Medicine, Kasetsart University, Bangkok 10900, Thailand

Full list of author information is available at the end of the article
}

(c) The Author(s). 2020 Open Access This article is licensed under a Creative Commons Attribution 4.0 International License, which permits use, sharing, adaptation, distribution and reproduction in any medium or format, as long as you give appropriate credit to the original author(s) and the source, provide a link to the Creative Commons licence, and indicate if changes were made. The images or other third party material in this article are included in the article's Creative Commons licence, unless indicated otherwise in a credit line to the material. If material is not included in the article's Creative Commons licence and your intended use is not permitted by statutory regulation or exceeds the permitted use, you will need to obtain permission directly from the copyright holder. To view a copy of this licence, visit http://creativecommons.org/licenses/by/4.0/ The Creative Commons Public Domain Dedication waiver (http://creativecommons.org/publicdomain/zero/1.0/) applies to the data made available in this article, unless otherwise stated in a credit line to the data. 


\section{Background}

The use of platelet-rich plasma (PRP) in clinical practice has increased recently [1-8]. PRP also is used in orthopedic surgery to treat bone, tendon, and ligament injuries [8-14]. Several clinical studies have found that PRP injections can improve functional outcomes and reduce symptoms when compared with hyaluronic acid and placebo controls [13]. Intra-articular injections of PRP can be useful in extracellular matrix remodeling; have the potential to promote cell proliferation, chemotaxis, cell differentiation, and angiogenesis; and can be a potent source of regenerative growth factors [12, 13, 15-17]. Several growth factors are released by PRP, such as platelet-derived growth factors, epidermal growth factors, fibroblast growth factors, insulin-like growth factors, vascular endothelial growth factors, transforming growth factors, and keratinocyte growth factors [8]. PRP usually is prepared using a one- or two-step centrifugation technique [1-8]. The preparation time for the onestep technique is shorter than for the two-step technique [2]. The one-step technique can be manually completed using a benchtop centrifuge, a single sterile pipette, and a single sterile tube [1]. Although the two-step centrifugation technique can increase platelet concentration [2], it is time consuming and may increase a chance of bacterial contamination. Commercially available PRP kits have been developed for semiclosed preparation in a one-step centrifugation, but they are expensive and require specialized equipment.

Carprofen is a selective cyclooxygenase- 2 inhibitor and widely used by veterinarians as an analgesic after orthopedic procedures [18-20]. It has a positive influence on the healing of cartilage [20]. Gradient centrifugations using insoluble emulsion have been used to separate PRP from whole blood [21]. The separation properties of emulsion are due to its phospholipid interface and water interface [22]. In one study, carprofen microspheres were prepared with an emulsion solvent evaporation technique using cellulose acetate phthalate as the polymer dissolved in dichloromethane $(1.5 \% \mathrm{w} / \mathrm{v})$ [23].
Injectable carprofen (emulsion formula) can be applied as a separation layer during PRP preparation, but currently, there is no standardized protocol for optimizing PRP preparation with a separation layer. Therefore, the objectives of this study were to (1) identify the optimal centrifugation force for the one-step PRP preparation, (2) compare the one-step syringe centrifugation technique with and without carprofen used as the separation layer, and (3) compare platelet morphology after onestep PRP preparation with and without carprofen.

\section{Results}

The mean \pm standard deviation (SD) platelet concentration of whole blood before centrifugation for the onestep PRP preparation was $230.79 \pm 41.48 \times 10^{3}$ cell $/ \mu \mathrm{l}$. The average fold-increase in platelet concentration ranged from 1.14 to 2.09 (Table 1). PRP centrifugation from $300 \mathrm{xg}$ to $1500 \mathrm{xg}$ led to an upward trend of plasma volume from 29.24 to $89.61 \%$ but caused a downward trend in platelet concentration from 98.83 to $54.55 \%$. The optimal centrifugal force for syringe centrifugation was found to be $900 \mathrm{xg}$, at which the plasma volume and platelet concentration were $1.9 \pm$ $0.28 \mathrm{ml}$ and $260.50 \pm 58.39 \times 10^{3}$ cell/ $\mu \mathrm{l}$, respectively (Fig. 1, Table 1). The platelet concentration, percentage of recovery, and platelet fold increase for one-step PRP preparation at $900 \mathrm{xg}$ were significantly different between the centrifugal forces at 300, 500, 1300, and 1500 xg $(p<0.0001)$ (Table 1).

The mean \pm SD platelet concentration of whole blood before centrifugation using the one-step PRP preparation with carprofen was $214.58 \pm 53.91 \times 10^{3}$ cell $/ \mu \mathrm{l}$. The average fold-increase in platelet concentration ranged from 2.34 to 8.19 (Table 2). The platelet concentration, platelet fold increase, and percentage of recovery in onestep PRP preparation with carprofen at $500 \mathrm{xg}$ were significantly different from those found at 300,700 , and $900 \times g(p<0.0001)$ (Table 2). The coefficient of variance (CV) in one-step PRP preparation without and with carprofen ranged from 0.82 to $1.71 \%$ and 1.87 to $2.42 \%$,

Table 1 Effects of different centrifugation forces in one-step platelet-rich plasma preparation $(N=14)$

\begin{tabular}{|c|c|c|c|c|}
\hline Force, $x g$ & $\begin{array}{l}\text { Platelet concentration, } \\
\times 10^{3} \mathrm{cell} / \mu \mathrm{l}\end{array}$ & Plasma, ml & Recovery, \% & Platelet fold-increase \\
\hline 300 & $376.50 \pm 73.52^{* * *}$ & $0.8 \pm 0.33^{* * *}$ & $56.45 \pm 7.59^{* * *}$ & $2.09 \pm 0.18^{* * *}$ \\
\hline 500 & $326.43 \pm 73.10^{* * *}$ & $1.1 \pm 0.38^{* * *}$ & $65.09 \pm 6.74^{* * *}$ & $1.81 \pm 0.20^{* * *}$ \\
\hline 700 & $284.43 \pm 60.54$ & $1.5 \pm 0.38^{* * *}$ & $75.27 \pm 6.85^{* *}$ & $1.58 \pm 0.17^{*}$ \\
\hline 900 & $260.50 \pm 58.39$ & $1.9 \pm 0.28$ & $81.65 \pm 4.91$ & $1.44 \pm 0.16$ \\
\hline 1100 & $236.56 \pm 47.04$ & $2.2 \pm 0.23^{*}$ & $88.55 \pm 4.44^{* * *}$ & $1.32 \pm 0.11^{*}$ \\
\hline 1300 & $214.49 \pm 42.77^{* * *}$ & $2.5 \pm 0.19^{* * *}$ & $93.38 \pm 3.96^{* * *}$ & $1.19 \pm 0.11^{* * *}$ \\
\hline 1500 & $205.52 \pm 41.57^{* * *}$ & $2.8 \pm 0.15^{* * *}$ & $96.85 \pm 2.54^{* * *}$ & $1.14 \pm 0.11^{* * *}$ \\
\hline
\end{tabular}

${ }^{\mathrm{a}}$ From the mean platelet concentration of $230.79 \pm 41.48 \times 10^{3}$ cell/ $\mu$ l before centrifugation. Statistical analyses were performed using one-way analysis of variance comparing with the optimal centrifugation force of $900 \mathrm{xg}$; data expressed as mean \pm standard deviation. $\mathrm{g}=$ gravitational force. ${ }^{*} p<0.05$, ${ }^{* *} p<0.01$, and ${ }^{* * *} p<$ 0.001 in post-hoc tests 




respectively (Table 2). As PRP centrifugation was increased from 300 to $900 \mathrm{xg}$, there was an upward trend in plasma volume, from 30.70 to $92.70 \%$, but a downward trend in platelet concentration, from 98.91 to $28.73 \%$ (Fig. 2). The optimal centrifugation force was identified as $500 \mathrm{xg}$, at which the plasma volume and platelet concentration were $0.62 \pm 0.16 \mathrm{ml}$ and $948.50 \pm$ $261.40 \times 10^{3}$ cell $/ \mu \mathrm{l}$, respectively (Fig. 2 , Table 3 ).

The mean red blood cell, white blood cell, and platelet concentrations were significantly different between the whole blood and products from PRP without carprofen at $900 \mathrm{xg}(p<0.0001)$ and between whole blood and PRP

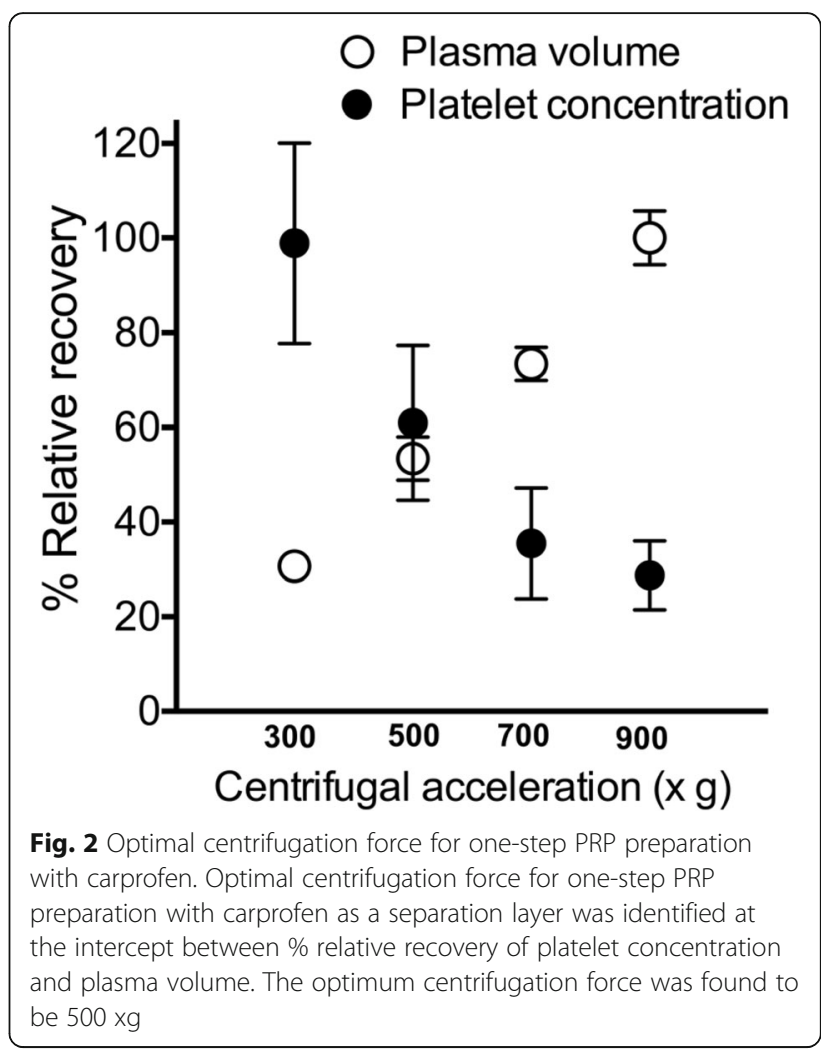

products with carprofen at $500 \mathrm{xg}(p<0.0001$; Table 3$)$. The morphology of glass-activated platelets using scanning electron microscopy (SEM) indicated that pseudopods emerging from the margins of the discoid platelets in one-step PRP preparation are similar to that found in one-step PRP preparation with carprofen (Fig. 3).

\section{Discussion}

Platelet-rich plasma (PRP) is defined as an autologous biological product derived from whole blood that has been centrifuged to remove red blood cells. PRP is a part

Table 2 Effects of four different centrifugation forces for one-step platelet-rich plasma preparation with and without carprofen $(N=$ 12)

\begin{tabular}{|c|c|c|c|c|}
\hline Force, $x g$ & Platelet concentration, $\times 10^{3} \mathrm{cell} / \mu \mathrm{l}$ & Platelet fold-increase & Recovery, \% & Coefficient of variance, $\%$ \\
\hline \multicolumn{5}{|c|}{ Without carprofen $^{a}$} \\
\hline 300 & $391.75 \pm 49.55^{* * *}$ & $2.02 \pm 0.28^{* * *}$ & $56.70 \pm 5.22^{* * *}$ & 0.82 \\
\hline 500 & $328.17 \pm 55.36^{* * *}$ & $1.74 \pm 0.16^{* * *}$ & $69.87 \pm 3.84^{* * *}$ & 1.38 \\
\hline 700 & $290.75 \pm 56.69^{*}$ & $1.54 \pm 0.17^{*}$ & $83.00 \pm 4.70^{* *}$ & 1.70 \\
\hline 900 & $260.13 \pm 44.85$ & $1.38 \pm 0.12$ & $88.66 \pm 3.49$ & 1.71 \\
\hline \multicolumn{5}{|c|}{ With carprofen ${ }^{b}$} \\
\hline 300 & $1556.10 \pm 339.55^{* * *}$ & $8.19 \pm 0.84^{* * *}$ & $89.39 \pm 7.08^{* * *}$ & 1.87 \\
\hline 500 & $948.50 \pm 261.40$ & $4.95 \pm 0.76$ & $97.80 \pm 1.72$ & 1.78 \\
\hline 700 & $552.29 \pm 187.22^{* * *}$ & $2.87 \pm 0.63^{* * *}$ & $86.19 \pm 2.71^{* * *}$ & 2.42 \\
\hline 900 & $447.13 \pm 116.64^{* * *}$ & $2.34 \pm 0.33^{* * *}$ & $82.80 \pm 3.88^{* * *}$ & 2.23 \\
\hline
\end{tabular}

${ }^{\mathrm{a} C o m p a r e d ~ w i t h ~ t h e ~ o p t i m a l ~ c e n t r i f u g a t i o n ~ f o r c e ~ o f ~} 900 \mathrm{xg} .{ }^{\mathrm{b}}$ Compared with the optimal centrifugation force of $500 \mathrm{xg}$. Platelet concentration, increase and $\%$ recovery expressed as mean \pm standard deviation. $g=$ gravitational force. ${ }^{*} p<0.05,{ }^{* *} p<0.01$, and ${ }^{* * *} p<0.001$ in post-hoc tests 
Table 3 Comparison of RBC, WBC, platelet concentration, and plasma volume between both syringe centrifugation methods

\begin{tabular}{llll}
\hline Parameters & Whole blood & One-step PRP preparation without carprofen ${ }^{a}$ & One-step PRP preparation with carprofen \\
\hline $\mathrm{RBC}, \times 10^{6} \mathrm{cell} / \mathrm{mm}^{3}$ & $6.15 \pm 0.85$ & $1.97 \pm 0.37^{* * *}$ & $0.58 \pm 0.24^{* * *}$ \\
WBC, $\times 10^{3} \mathrm{cell} / \mathrm{mm}^{3}$ & $10.34 \pm 2.84$ & $0.36 \pm 0.19^{* * *}$ & $0.72 \pm 0.16^{* * *}$ \\
Platelet, $\times 10^{3} \mathrm{cell} / \mu \mathrm{l}$ & $214.58 \pm 53.91$ & $260.13 \pm 44.85^{* * *}$ & $948.50 \pm 261.40^{* * *}$ \\
Plasma, $\mathrm{ml}$ & $2.95 \pm 0.25$ & $1.97 \pm 0.37^{* * *}$ & $0.62 \pm 0.16^{* * *}$ \\
\hline
\end{tabular}

${ }^{\mathrm{a}}$ Compared with the optimal centrifugation force of $900 \mathrm{xg} .{ }^{\mathrm{b}}$ Compared with the optimal centrifugation force of $500 \mathrm{xg}$. Data expressed as mean \pm standard deviation. $\mathrm{g}=$ gravitational force; $\mathrm{PRP}=$ platelet-rich plasma; $\mathrm{RBC}=$ red blood cell; $\mathrm{WBC}=$ white blood cell. ${ }^{*} p<0.05$, ** $p<0.01$, and ${ }^{* * *} p<0.001$ in post-hoc tests

of the plasma fraction with a platelet concentration higher than that of whole blood [8]. The efficiencies of red blood cell separation and platelet concentration depend on the density gradient, speed, number of spins, separation time, volume of whole blood, initial platelet concentration, distance between the particles, and the centrifuge rotor to the volume of processed whole blood,

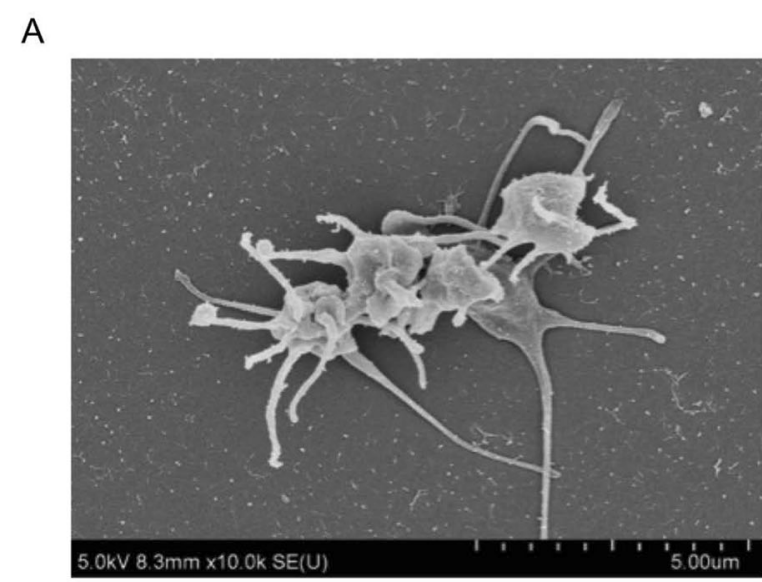

B

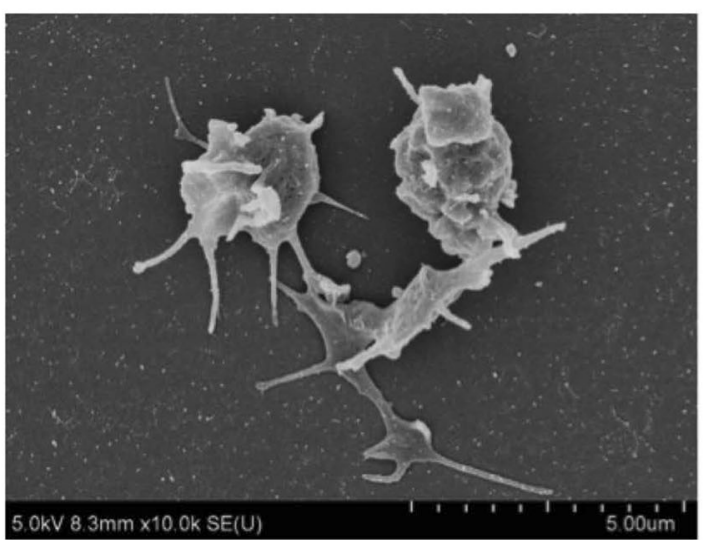

Fig. 3 Scanning electron micrographs of platelets. Scanning electron micrographs of platelets in one-step PRP preparation without (a) and with (b) carprofen. a Platelets showed pseudopods emerging from the margins of the discoid platelets $(X 10,000)$. b Platelets showed pseudopods emerging from the margins of the discoid platelets (X 10,000) including clotting factors $[24,25]$. The results of this study show that a one-step PRP preparation using a disposable $6 \mathrm{ml}$ syringe with and without carprofen can separate plasma layers and increase platelet yield. The optimal centrifugal forces with and without carprofen were identified as $500 \mathrm{xg}$ and $900 \mathrm{xg}$, respectively. The one-step PRP preparation without carprofen led to a 1.38-fold increase in platelet concentration; however, the addition of carprofen led to a 4.95-fold increase. In a previous study, the \% CV in one-step PRP preparation was low $(<15 \%)$ between sample replicates [26]. In present study, it was confirmed through analysis of \% $\mathrm{CV}$ that there was comparable precision and variation between the one-step PRP preparation with and that without carprofen [26]. The morphology of platelets indicated that pseudopods were emerging from the margins of the discoid platelets from PRP preparation without carprofen and with carprofen, suggesting normal platelet function.

Centrifugation is regularly used to separate components of a substance on the basis of particle size and density [27-29]. It is applied to separate the blood into cells and plasma supernatant or serum. There are several protocols available to prepare PRP [2, 3, 7, 30-35]. Using leukocyte and fibrin content, PRP can be categorized in to four groups including leukocyte-rich PRP, leukocyte reduced $\mathrm{PRP}$, leukocyte platelet-rich fibrin and pure platelet-rich fibrin [36]. In the present study, a one-step PRP preparation method was used to identify the optimal centrifugation force in a disposable $6 \mathrm{ml}$ syringe. Since there was no special filter for leukocytes used in a single step PRP preparation, our method would produce leukocyte-rich PRP. Moreover, carprofen was applied as a separation layer, dividing plasma and cellular elements. The present method has several advantages, such as increased yield of platelet concentration, reduced red and white blood cell concentrations, and reduced centrifuge force and time.

The efficacy of the one-step [34] and two-step [2] PRP preparation from human blood samples have been previously. A one-step process using $4.5 \mathrm{ml}$ of whole blood with $3.8 \%$ trisodium citrate led to a 2.67 -fold increase in platelet yield from the baseline value [34]. A two-step process using $4.5 \mathrm{ml}$ of whole blood with $0.5 \mathrm{ml}$ citrate 
solution led to an increase in platelet concentration by a factor of 5.4-7.3 [37]. In a study of blood samples from dogs, a two-step centrifugation process using $9 \mathrm{ml}$ of whole blood with $1 \mathrm{ml}$ of citrate phosphate dextrose adenine-1 (CPDA-1) obtained a PRP volume of $0.3 \mathrm{ml}$ with a concentration about 5.26-6.94 times higher compared with the original $9 \mathrm{ml}$ whole blood sample In the present study, a one-step centrifugation process using 5 $\mathrm{ml}$ of whole blood with $4.5 \%$ of CPDA-1 in a disposable syringe led to a 1.76-fold increase in platelet concentration, which was comparable to the results of previous research Interestingly, the one-step process with carprofen led to a 4.95-fold increase in PRP concentration. It should be noted that amount of RBC and WBC contaminations were lower in a one-step PRP preparation with carprofen. Addition of carprofen as a separation layer helped improve plasma separation and increase platelet concentration. Thus, our results demonstrated that higher PRP concentrations could be achieved with only one centrifugation spin.

In the present study, statistic calculator software was applied to compute the appropriate sample size for the one-step PRP preparation to achieve the target power of $90 \%$ for clinical study. Nonetheless, different groups of animals were used during the baseline study for the onestep PRP preparation with syringe centrifugation and during the comparison between carprofen-free test and carprofen-based test, leading to the use of several canine blood donors. There are several ways to improve the methodology of the present study that would help minimize the number of canine blood donors enrolled in the study. Studying in any one breed of dogs could lower genetic variations leading to lower variations of the platelet count. The one-step PRP preparation, demonstrated in a present study, requires only small amount of blood $(5 \mathrm{~mL})$ for a syringe centrifugation, therefore, it is possible to retrieve a serial blood sampling from the same animal using an indwelling catheter leading to a lower variation between subjects and improving the statistical power of the results. Moreover, the one-step PRP preparation using syringe centrifugation also offers the opportunity to apply an autologous PRP treatment for a small sized dog.

An SEM study revealed that resting platelets had a discoid shape with a smooth surface around $1-3 \mu \mathrm{m}$ in size [38]. The resting platelets can be activated by shear stress, thrombin, or endothelial membrane-induced morphological changes of platelets [39-42]. Activated platelets become spherical as actin filaments. Cell membranes protrude actin filament known as pseudopods [43]. In the present study, platelet activation was determined using a glass slide. An adhesion and activation of platelet on glass surface was revealed on SEM images demonstrating a discoid shape projecting marginal pseudopods. Pseudopods were identified in the platelets from the PRP preparation using carprofen. Therefore, the use of carprofen as a separation layer had a minimal effect on platelet activation in the present study.

Bacterial contamination is a leading cause of transfusion-related mortality [44]. Conventional methods using two-step PRP preparation increase the risk for environmental bacterial contamination, especially during the transfer of the product between tubes in the first step of preparation [44-46]. This risk can be greatly reduced if transfers are conducted in a laminar flow hood under sterile conditions [7]. In the present study, a onestep PRP preparation protocol using a disposable $6 \mathrm{ml}$ syringe was successfully developed. The one-step syringe centrifugation eliminates the multi-tube transfer process; therefore, the risk of bacterial contamination is greatly reduced. It is important that the venipuncture site be thoroughly cleaned before collecting blood with a sterile needle and syringe. That way, a direct connection is made between the bloodstream of the patient and the sterile equipment. After centrifugation, the blood components can be squeezed into another syringe using a sterile three-way connector without affecting sterility, because the primary blood tube is never opened and the entire process occurs in a closed system [47]. If the syringe is accidentally exposed to the environment, it is considered to be an open system and the product should be discarded to avoid bacterial contaminations. One limitation of the present study was the lack of a bacteria culture. Thus, further studies should assess the effectiveness of the one-step PRP preparation method using syringe centrifugation in reducing bacterial contamination.

Numerous studies have demonstrated that PRP releases several growth factors, especially platelet-derived growth factors. In recent years, the use of PRP in the treatment of degenerative osteoarthritis has increased. Several clinical studies have found that PRP injections have improved functional outcomes and reduced symptoms when compared with hyaluronic acid and placebo controls [13]. Intra-articular injection of PRP also prevented cytotoxic effect of lidocaine on chondrocytes [48] Thus, intra-articular injections of PRP can be useful in angiogenesis and extracellular matrix remodeling, cell proliferation, and differentiation for osteoarthritis [12, 13, 15, 16]. Applications of PRP in fracture repair had been shown in both dogs [49] and rabbit [48] by promoting bone healing. Interestingly, injection of PRP also promoted wound healing of soft tissue defects $[50,51]$ as well as periodontal regeneration [52]. Since the present study did not evaluate the alteration of growth factors in PRP, it remains unknown whether the use of carprofen as a separation layer affecting the function of platelet-derived growth factors in PRP products. Moreover, several studies including platelet function, markers 
of platelet storage lesion, and microbial contamination should be evaluated for the safety of the patients [53] should be conducted before clinical application of the single step PRP product.

\section{Conclusions}

The present study revealed that a one-step PRP preparation with carprofen significantly increased platelet yield. The syringe centrifugation method does not require expensive equipment or high technical abilities. Thus, this method can be easily adopted in a veterinary clinic setting. The clinical usefulness of the PRP products derived from the methods used in this study should be investigated further.

\section{Methods}

\section{Animals}

All procedures were approved by the Kasetsart University Institutional Animal Care and Use Committee under approval number \#ACKU61-VET-031. A total of 29 healthy dogs (13 males and 16 females) were enrolled in the present study. The dogs weighed $25.0 \pm 6.1 \mathrm{~kg}($ mean $\pm \mathrm{SD})$ and were $3.5 \pm 1.4$ years old Among these 29 dogs were an Alaskan Malamute [1], American Bully [1], Boxer [1], crossbreed [6], Golden Retrievers [7], Labrador Retrievers [3], a St. Bernard [1], and Siberian Huskies [9]. All dog owners signed an informed consent document before the study was conducted. History taking and physical examination were performed by a licensed veterinarian. Complete blood count $(\mathrm{CBC})$, serum biochemistry profiles and quality of blood smear were evaluated before canine blood donation at Kasetsart Pet Blood Bank. Twenty nine bags of blood from these dogs, 14 were used for identifying the optimum force for the one-step PRP preparation with syringe, 12 were used in the one-step syringe centrifugation technique with carprofen, and 3 were used for analysis of platelet morphology.

\section{Blood collection}

None of the dogs were on any medication, including aspirin or other nonsteroidal anti-inflammatory drugs, for 10 days before the experiment. Each dog was given $0.1 \mathrm{mg} / \mathrm{kg}$ of xylazine hydrochloride (XLAZINE ${ }^{\oplus}$ LBS laboratory, Bangkok, Thailand) intravenously. Approximately $315 \mathrm{ml}$ of whole blood was collected by jugular venipuncture with a 20-gauge needle and deposited directly into $350 \mathrm{ml}$ blood bags containing $35 \mathrm{ml}$ of CPDA-1 (Terumo cooperation, Tokyo, Japan), with a ratio of CPDA-1 to whole blood of 1:9 [7].

\section{Determination of optimum force for the one-step PRP preparation with syringe}

Approximately, $80 \mathrm{ml}$ of donor blood was obtained from each blood bag and $5 \mathrm{ml}$ of blood was drawn into seven 6-ml syringes using an aseptic technique. The present study had modified a syringe method for PRP preparation from previous study [54] and the centrifugation speed and time were adapted from previous studies [7, 54]. To identify the optimal centrifugation force for the one-step PRP preparation, samples were centrifuged at $300,500,700,900,1100,1300$, and $1500 \mathrm{xg}$ for $5 \mathrm{~min}$ at $20^{\circ} \mathrm{C}$. The centrifuge was allowed to stop spinning without operator intervention. After centrifugation, whole plasma fraction containing plasma and platelets was transferred to 3-ml syringe via a sterile three-way. An automated hematology analyzer (Abbott Cell-Dyn 3700, Abbott Park, Illinois, USA) was used to evaluate the number of platelets, red blood cells, and white blood cells. Plasma volume also was measured using laboratory analytical digital balance scales (FX-5000I, Reno, Bangkok, Thailand).

\section{Determination of optimum force for the one-step PRP preparation with carprofen}

Twelve healthy dogs (4 males and 8 females) aged 1-7 years with a mean $( \pm$ SD) body weight of $26.58( \pm 7.35)$ $\mathrm{kg}$ were used to determine the optimum centrifugal force with carprofen (Table 1). Among these 12 dogs were an American Bulldog [1], a Boxer [1], a crossbreed [1], Golden Retrievers [4], a Labrador Retriever [1], and Siberian Huskies [4]. Blood containing CPDA-1 (5 ml) was transferred into four $6 \mathrm{ml}$ syringes. Carprofen $\left(200 \mu \mathrm{l}\right.$; Rimadyl ${ }^{\circledR}$, Norbrook Laboratories Limited Newry, Northern Ireland, UK) was added to act as a separation layer. The blood samples were divided into four aliquots, two containing $5 \mathrm{ml}$ of whole blood without carprofen and two containing $5 \mathrm{ml}$ of whole blood with $0.2 \mathrm{ml}$ of carprofen. To compare the effectiveness of the one-step PRP preparation with and without carprofen, blood samples were centrifuged at four different centrifugation forces $(300,500,700$, and $900 \mathrm{xg})$, with two replications for each comparison, for $5 \mathrm{~min}$ at $20^{\circ} \mathrm{C}$. After centrifugation, the samples were treated in the same fashion as the one-step PRP preparation without carprofen described above. The overall time from blood collection until the retrieval of PRP was under $4 \mathrm{~h}$, hence, the present method is in accordance with the international guideline for safety transfusion $[55,56]$.

\section{Scanning electron microscopy (SEM) observation}

Three healthy dogs were used to evaluate the morphology of platelets. Five milliliters of blood samples containing CPDA-1 with and without $0.2 \mathrm{ml}$ of carprofen were centrifuged at $500 \mathrm{xg}$ for $5 \mathrm{~min}$ at $20^{\circ} \mathrm{C}$. Twenty- 
five microliters of PRP was dropped on a cover glass and allowed to dry. Blood samples then were fixed using $1.5 \%$ glutaraldehyde (Sigma-Aldrich, Missouri, USA) in $0.1 \mathrm{M}$ phosphate buffer, pH 7.2 (Merk, Frankfurter, Germany), at $4^{\circ} \mathrm{C}$ for $24 \mathrm{~h}$. The specimens were dehydrated through a graded ethanol series, mounted onto aluminum stubs, sputter-coated with platinum, and viewed with a scanning electron microscope (Hitachi SU8020, Tokyo, Japan).

\section{Statistical methods}

The G*Power3.1 (Faul, Erdfelder, Lang and Buchner, 2007) was used to estimate the required sample size using $t$-tests for a paired samples with a power of $90 \%$, and an alpha error of $5 \%$ to detect a difference of 1.0 standard deviation of the average value of platelet count. The data were analyzed using $\mathrm{R}$ version 3.6.1 ( $\mathrm{R}$ core team, Vienna, Austria). A Shapiro-Wilk test was used to determine normality. A one-way analysis of variance (ANOVA) was used to compare the different centrifugation forces for the one-step PRP preparation with and without carprofen, as appropriate. The optimal forces were those that gave the maximum values of platelet concentration and plasma. The percentage of platelet recovery in the product of PRP was calculated by multiplying the platelet concentration of the plasma by the plasma volume and then dividing this by the product of the platelet concentration of whole blood and the plasma volume of whole blood and multiplying by 100 .

The CV was the measure of relative variability of PRP products for each centrifugation force in the one-step PRP preparation with carprofen. The \% CV was calculated by dividing the standard deviation by the mean and multiplying by 100 [26]. Statistical significance was set as $p<0.05$.

\section{Abbreviations \\ CV: Coefficient of variation; ml: milliliter; $\mu$ l: microliter; mg: milligram; PRP: Platelet-rich plasma; RBC: Red blood cell; SD: Standard deviation; SEM: Scanning electron microscopy; WBC: White blood cell; ${ }^{\circ} \mathrm{C}$ : Degrees Celsius; $x g$ : relative centrifugal force}

\section{Acknowledgements \\ The authors are grateful to Dr. Tanakorn Wattanapornpilom and Sarawut Yangtara for assisting with blood collection, to Dr. Chalermpol Lekcharoensuk for commenting on the statistical analysis, and to Edward McNeil for english proofreading. We gratefully thank the Canine and Mounted Police Subdivision and the pet owners for donating blood.}

\section{Authors' contributions \\ JA: designed study, conducted literature review, performed study, interpreted data, and drafted manuscript. PS: designed study and reviewed manuscript. PC: performed study and reviewed manuscript. NT: designed study, interpreted data and reviewed manuscript. All authors have read and approved the final manuscript.}

\section{Funding}

The present study was financially supported by the Faculty of Veterinary Medicine, Kasetsart University.

\section{Availability of data and materials}

The data used and/or analyzed in the present study are available from the corresponding author on reasonable request.

\section{Ethics approval and consent to participate}

The protocol was approved by the Kasetsart University Institutional Animal Care and Use Committee (approval number \#ACKU61-VET-031) and by the Ethical Review Board of the Office of National Research Council of Thailand (NRCT license U1-00500-2558). Informed written consent was obtained from all dog owners and the experiment complied with the Kasetsart University Institutional Animal Care and Use Standards.

Consent for publication

Not applicable.

\section{Competing interests}

The authors declare that they have no competing interests.

\section{Author details}

${ }^{1}$ Graduate Student in Veterinary Clinical Studies, Faculty of Veterinary Medicine, Kasetsart 462 University, Bangkok 10900, Thailand. ${ }^{2}$ Department of Companion Animal Clinical Sciences, Faculty of Veterinary Medicine, Kasetsart University, Bangkok 10900, Thailand. ${ }^{3}$ Kasetsart University Veterinary Teaching Hospital, Faculty of Veterinary Medicine, Kasetsart University, Bangkok 10900, Thailand.

Received: 28 September 2019 Accepted: 29 April 2020

Published online: 06 May 2020

\section{References}

1. Johnston SA. Veterinary surgery: small animal expert consult-E-book: Elsevier health sciences; 2017.

2. Cook CS, Smith PA. Clinical update: why PRP should be your first choice for injection therapy in treating osteoarthritis of the knee. Curr Rev Musculoskelet Med. 2018:11(4):583-92.

3. Carr BJ, Canapp SO Jr, Mason DR, Cox C, Hess T. Canine platelet-rich plasma systems: a prospective analysis. Front Vet Sci. 2016;2:73.

4. Abbasipour-Dalivand S, Mohammadi R, Mohammadi V. Effects of local administration of platelet rich plasma on functional recovery after bridging sciatic nerve defect using silicone rubber chamber; an experimental study. Bulletin Emerg Trauma. 2015;3(1):1.

5. Sardari K, Emami MR, Kazemi H, Movasagi AR, Goli AA, Lotfi A, et al. Effects of platelet-rich plasma (PRP) on cutaneous regeneration and wound healing in dogs treated with dexamethasone. Comp Clin Pathol. 2011;20(2):155-62.

6. Gerard D, Carlson ER, Gotcher JE, Jacobs M. Effects of platelet-rich plasma on the healing of autologous bone grafted mandibular defects in dogs. $J$ Oral Maxillofac Surg. 2006;64(3):443-51.

7. Shin H-S, Woo H-M, Kang B-J. Optimisation of a double-centrifugation method for preparation of canine platelet-rich plasma. BMC Vet Res. 2017; 13(1):198.

8. Chicharro-Alcántara D, Rubio-Zaragoza M, Damiá-Giménez E, Carrillo-Poveda JM, Cuervo-Serrato B, Peláez-Gorrea P, et al. Platelet rich plasma: new insights for cutaneous wound healing management. J Funct Biomater. 2018;9(1):10

9. Whitman DH, Berry RL, Green DM. Platelet gel: an autologous alternative to fibrin glue with applications in oral and maxillofacial surgery. J Oral Maxillofac Surg. 1997:55(11):1294-9.

10. Anitua E. Plasma rich in growth factors: preliminary results of use in the preparation of future sites for implants. Int J Oral Maxillofac Implants. 1999; 14(4):529-35.

11. Kajikawa Y, Morihara T, Sakamoto H, Ki M, Oshima Y, Yoshida A, et al. Platelet-rich plasma enhances the initial mobilization of circulation-derived cells for tendon healing. J Cell Physiol. 2008;215(3):837-45.

12. Filardo G, Kon E, Buda R, Timoncini A, Di Martino A, Cenacchi A, et al. Platelet-rich plasma intra-articular knee injections for the treatment of degenerative cartilage lesions and osteoarthritis. Knee Surg Sports Traumatol Arthrosc. 2011;19(4):528-35.

13. O'Connell B, Wragg NM, Wilson SL. The use of PRP injections in the management of knee osteoarthritis. Cell Tissue Res. 2019;376(2):143-52. 
14. Davis VL, Abukabda AB, Radio NM, Witt-Enderby PA, Clafshenkel WP, Cairone JV, et al. Platelet-rich preparations to improve healing. Part I: workable options for every size practice. J Oral Implantol. 2014;40(4):500-10.

15. Shen L, Yuan T, Chen S, Xie X, Zhang C. The temporal effect of platelet-rich plasma on pain and physical function in the treatment of knee osteoarthritis: systematic review and meta-analysis of randomized controlled trials. J Orthop Surg Res. 2017;12(1):16.

16. Ayhan E, Kesmezacar H, Akgun I. Intraarticular injections (corticosteroid, hyaluronic acid, platelet rich plasma) for the knee osteoarthritis. World J Orthop. 2014;5(3):351.

17. Kushida S, Kakudo N, Morimoto N, Hara T, Ogawa T, Mitsui T, et al. Platelet and growth factor concentrations in activated platelet-rich plasma: a comparison of seven commercial separation systems. J Artif Organs. 2014;17(2):186-92.

18. Pang LY, Argyle SA, Kamida A, Morrison KON, Argyle DJ. The long-acting COX-2 inhibitor mavacoxib (Trocoxil ${ }^{T M}$ ) has anti-proliferative and proapoptotic effects on canine cancer cell lines and cancer stem cells in vitro. BMC Vet Res. 2014;10(1):184.

19. Thengchaisri N, Sattasathuchana P, Niyom S, Chantornvong W. Comparison of carprofen, vedaprofen and tepoxalin for postoperative analgesia and serum PGE2 level in dogs after ovariohysterectomy. Thai J Vet Med. 2010; 40(2):159-64.

20. Sidler M, Fouché N, Meth I, von Hahn F, von Rechenberg B, Kronen PW. Preliminary study on carprofen concentration measurements after transcutaneous treatment with Vetdrop ${ }^{\bullet}$ in a microfracture joint defect model in sheep. BMC Vet Res. 2014;10(1):268.

21. Qiu P, Mao C. Viscosity gradient as a novel mechanism for the centrifugation-based separation of nanoparticles. Adv Mater. 2011;23(42): 4880-5

22. Pichot R, Watson R, Norton I. Phospholipids at the interface: current trends and challenges. Int J Mol Sci. 2013;14(6):11767-94.

23. Sundar RS, Murugesan A, Venkatesan P, Manavalan R. Formulation development and evaluation of carprofen microspheres. Int J Pharm Tech Res. 2010;2(3):1674-6.

24. Hall MP, Band PA, Meislin RJ, Jazrawi LM, Cardone DA. Platelet-rich plasma: current concepts and application in sports medicine. J Am Acad Orthop Surg. 2009;17(10):602-8.

25. Lippi G, Salvagno GL, Montagnana M, Guidi GC. Preparation of a quality sample: effect of centrifugation time on stat clinical chemistry testing. Lab Med. 2007;38(3):172-6.

26. Abdi H. Coefficient of variation. Encyclopedia Res Des. 2010;1:169-71.

27. Schumaker $V$, Rees $A$. Theory of differential centrifugation in angle-head rotors. Anal Biochem. 1969;31:279-85.

28. Laue T. Analytical centrifugation: equilibrium approach. Curr Protoc Protein Sci. 1999:18(1):20.3. 1-3. 13.

29. Ambler C. Theory of centrifugation. Ind Eng Chem. 1961;53(6):430-3

30. Nikolidakis D, Jansen JA. The biology of platelet-rich plasma and its application in oral surgery: literature review. Tissue Eng B Rev. 2008;14(3):249-58.

31. Sampson S, Reed M, Silvers H, Meng M, Mandelbaum B. Injection of platelet-rich plasma in patients with primary and secondary knee osteoarthritis: a pilot study. Am J Phys Med Rehabil. 2010;89(12):961-9.

32. Casati L, Celotti F, Negri-Cesi P, Sacchi MC, Castano P, Colciago A. Platelet derived growth factor (PDGF) contained in platelet rich plasma (PRP) stimulates migration of osteoblasts by reorganizing actin cytoskeleton. Cell Adhes Migr. 2014;8(6):595-602.

33. Sampson S, Gerhardt M, Mandelbaum B. Platelet rich plasma injection grafts for musculoskeletal injuries: a review. Curr Rev Musculoskelet Med. 2008; 1(3-4):165-74.

34. Anitua E, Prado R, Sánchez M, Orive G. Platelet-rich plasma: preparation and formulation. Oper Tech Orthop. 2012;22(1):25-32.

35. Jo CH, Roh YH, Kim JE, Shin S, Yoon KS. Optimizing platelet-rich plasma gel formation by varying time and gravitational forces during centrifugation. J Oral Implant. 2013;39(5):525-32.

36. Resnik RR. Dental Implant Intraoperative Complications. Misch's Avoiding Complications in Oral Implantology: Elsevier; 2018. p. 194-233.

37. Amable PR, Carias RBV, Teixeira MVT, da Cruz PI, do RJFC A, Granjeiro JM, et al. Platelet-rich plasma preparation for regenerative medicine: optimization and quantification of cytokines and growth factors. Stem Cell Res Ther. 2013;4(3):67.

38. Everts PA, Knape JT, Weibrich G, Schönberger JP, Hoffmann J, Overdevest $E P$, et al. Platelet-rich plasma and platelet gel: a review. J Extra Corpor Technol. 2006;38(2):174.
39. Nobili M, Sheriff J, Morbiducci U, Redaelli A, Bluestein D. Platelet activation due to hemodynamic shear stresses: damage accumulation model and comparison to in vitro measurements. ASAIO J. 2008;54(1):64.

40. Lu Q, Hofferbert BV, Koo G, Malinauskas RA. In vitro shear stress-induced platelet activation: sensitivity of human and bovine blood. Artif Organs. 2013;37(10):894-903.

41. Miyazaki Y, Nomura S, Miyake T, Kagawa H, Kitada C, Taniguchi H, et al. High shear stress can initiate both platelet aggregation and shedding of procoagulant containing microparticles. Blood. 1996;88(9):3456-64.

42. Ruggeri ZM, Orje JN, Habermann R, Federici AB, Reininger AJ. Activationindependent platelet adhesion and aggregation under elevated shear stress. Blood. 2006;108(6):1903-10.

43. Shin E-K, Park H, Noh J-Y, Lim K-M, Chung J-H. Platelet shape changes and cytoskeleton dynamics as novel therapeutic targets for anti-thrombotic drugs. Biomol Ther. 2017;25(3):223.

44. Shan H, Wang J-X, Ren F-R, Zhang Y-Z, Zhao H-Y, Gao G-J, et al. Blood banking in China. Lancet. 2002;360(9347):1770-5.

45. Enoch S, Grey JE, Harding KG. ABC of wound healing: recent advances and emerging treatments. BMJ. 2006;332(7547):962.

46. Farzad BB, Farshad B, Zahra B, Nahid A, Mahsa KB. Bacterial contamination of platelet products in the blood transfusion Center of Isfahan, Iran. GMS hygiene and infection control; 2016. p. 11.

47. Barrington JE. Sterilizable, medical connector for blood processing. Google Patents; 1976.

48. Szponder T, Wessely-Szponder J, SOBCZYŃSKA-RAK A, ŻYLIŃSKA B, RADZKI RP, Polkowska I. Application of platelet-rich plasma and tricalcium phosphate in the treatment of comminuted fractures in animals. in vivo. 2018;32(6):1449-55.

49. López S, Vilar JM, Sopena JJ, Damià E, Chicharro D, Carrillo JM, et al. Assessment of the efficacy of platelet-rich plasma in the treatment of traumatic canine fractures. Int J Mol Sci. 2019;20(5):1075.

50. Tsai H-C, Chang GR-L, Fan H-C, Ou-Yang H, Huang L-C, Wu S-C, et al. A mini-pig model for evaluating the efficacy of autologous platelet patches on induced acute full thickness wound healing. BMC Vet Res. 2019;15(1): 191.

51. Yao D, Hao D, Zhao F, Hao X, Feng G, Chu W, et al. Effects of platelet-rich plasma combined with polylactic acid/polycaprolactone on healing of pig deep soft tissue defect caused by fragment injury. Zhonghua shao shang za zhi= Zhonghua shaoshang zazhi. Chin J Burns. 2019:35(1):31-9.

52. Rezaei M, Jamshidi S, Saffarpour A, Ashouri M, Rahbarghazi R, Rokn AR, et al. Transplantation of Bone Marrow-Derived Mesenchymal Stem Cells, PlateletRich Plasma, and Fibrin Glue for Periodontal Regeneration. Int J Periodontics Restorative Dent. 2019;39(1):e32-e45.

53. Bozorgmanesh R, Magdesian KG, Sutton-Burges JW, Owens SD, Tablin F. Equine platelet concentrate preparation and validation. J Vet Intern Med. 2019:33(3):1500-6.

54. Fukaya M, Ito A. A new economic method for preparing platelet-rich plasma. Plast Reconstr Surg Global Open. 2014;2(6):e162.

55. Lanevschi A, Wardrop KJ. Principles of transfusion medicine in small animals. Can Vet J. 2001:42(6):447.

56. Davidow B. Transfusion medicine in small animals. Vet Clin North Am Small Anim Pract. 2013:43(4):735-56

\section{Publisher's Note}

Springer Nature remains neutral with regard to jurisdictional claims in published maps and institutional affiliations.

Ready to submit your research? Choose BMC and benefit from:

- fast, convenient online submission

- thorough peer review by experienced researchers in your field

- rapid publication on acceptance

- support for research data, including large and complex data types

- gold Open Access which fosters wider collaboration and increased citations

- maximum visibility for your research: over $100 \mathrm{M}$ website views per year

At BMC, research is always in progress.

Learn more biomedcentral.com/submissions 